\title{
Clinical assessment of submerged vs non-submerged implants placed in pristine bone \\ P. CARDELlI, ${ }^{1}$ E. CECCHETTI, ${ }^{1}{ }^{1}$. MONTANI, ${ }^{1}$ E. BRAMANTI, ${ }^{2}$ and $\underline{\text { C. ARCURI }}{ }^{1}$
}

$1 \overline{\bar{D}}$ pepartment of Clinical Science and Translational Medicine, University of Rome "Tor Vergata”, UOCC Odontostomatology “S. Giovanni CalibitaFatebenefratelli" Hospital, Rome, Italy

2 Department of Experimental Medical-Surgical and Oral Dental Sciences, University of Messina, Messina, Italy

Copyright @2013 CIC Edizioni Internazionali, Rome, Italy

The medium-long term success of osseointegrated dental implants is evaluated on the basis of the degree of osseointegration over time, assessed by radiographic or instrumental analysis (ISQ). Over the years, the question has always been which surgical technique can provide a better performance in the medium-long term and, thanks to literature studies, it has been evidenced that there are no differences between "one stage" and "two stage" interventions. The purpose of this study is to evaluate clinical and radiographic parameters, referring to interventions for the insertion of dental implants characterized by a new kind of implant surface (Synthegra ${ }^{\circledR}$ GEASS, Udine). The prospective study, not randomized and controlled, referred to the insertion of 18 implants on 9 patients with mono or bilateral edentulism, with measurements at 1, 3,6 and 12 months and an overall follow-up at 3 years, in order to evaluate the different degree of crestal bone resorption using the submerged and transmucosal surgical technique. The results of our study show that there are no differences in the resorption of the two surgical techniques, with an average bone resorption of 2,05 $\pm 0,16 \mathrm{~mm}$, comparable with values reported in literature.

Keywords: submerged healing abutment, non-submerged healing abutment, dental implant, crestal bone levels

Long and mid term success of osseointegrated implants, is generally evaluated following osseointegration rate during time measured on radiographic and instrumental (ISQ) analysis. In recent years, several authors focused their investigation on factors affecting the achievement and maintenance of correct osseointegration. Their conclusion indicate different conditions:

- implant type;

- surgical technique;

- implant surface;

- implant connection.

No significant differences in mid or long implant success and survival have been reported in literature between submerged and non-submerged implant $\left({ }^{1}\right)$.

Several surgical techniques have been examined, and any kind of technique showed an initial crestal bone resorption, as evidenced by Albrektsson, with a range value between $1 \mathrm{~mm}$ during healing period and $0.1 \mathrm{~mm}$ per year in the following years $(\underline{2}, \underline{3})$.

Other studies demonstrated, by means of radiographic analysis, that bone resorption starts at peri-implant crestal bone after abutment insertion, independently from the surgical technique used $\left({ }^{4}\right)$. 
More recent papers focused on the individuation of the best mid-long term osseointegration related to implant connection and surface.

The aim of this work is to assess clinical and radiographic parameters of dental implants characterized by a new kind of surface (Synthegra ${ }^{\circledR}$, GEASS, Udine, Italy) (Fig. 1). The selected parameters have been measured during healing period following two different surgical procedures: submerged and non-submerged technique, in order to analyze peri-implant vertical crestal bone resorption $\left(\frac{5}{}\right)$.

o

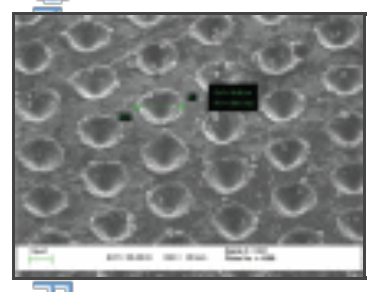

\section{Figure 1}

Synthegra surface.

Go to: $\nabla$ Go to: $\square$

The prospective controlled not randomized study have been performed in the Department of Prosthodontics of

"S. Giovanni Calibita Fate -benefratelli" Hospital of Rome. Sixteen implants have been inserted in 8 patients presenting mono and bilateral edentulism. Every patient collected three years follow-up records.

The following inclusion criteria have been selected:

- age > 21 years;

- non smoking patients;

- not need of regenerative procedures (hard or soft tissue) in the implant site;

- prosthetic rehabilitation of two or more implants;

- residual bone thickness (vestibular and lingual) more than 1,5 mm;

- inter-implant distance of at least $3 \mathrm{~mm}$;

- distance between tooth and implant of at least $2 \mathrm{~mm}$.

Following literature, the exclusion criteria have been represented by general and local contraindications (absolute and relative) to implant insertion.

The surgical protocol was performed respecting the indications provided by the manufacturer (GEASS $($ ), Udine, Italy). Dental implants used in our study have been constituted by Geass Way Milano Synthegra surface with diameter 3.4 - 3.8 - 4.5 - $5.5 \mathrm{~mm}$. The surgical procedure of soft and hard tissues was based on minimal invasive approach, then the two dental implants for patient have been inserted the first with submerged technique and the second one with non-submerged technique.

In case of submerged procedure the reentry has been performed six weeks after the insertion, with further two weeks in case of healing screw application. The functional loading has been performed 8 weeks from the insertion.

The clinical parameters examined were:

- suppuration;

- mPII;

- $\mathrm{mBII}$

- peri-implant probing depth;

- attachment level;

- mucosal cheratinization;

- cortical bone loss (CBL).

Crestal bone loss has been measured by means of individualized digital periapical x-rays on Digora ${ }^{\circledR}$ software. The measure selected was the distance between the implant shoulder and the most coronal bone contact point on mesial and distal surface. 
Clinical measurements have been performed by 6 points probing using PCP $15 \mathrm{UNC}$ probes by two different operators in two different times. Radiographic measurements have been examined at the implant insertion (T0) and at a distance of 1, 3, 6, and 12 months; clinical measurements have been performed at 2 (to favor a correct gingival attachment), 6 and 12 months. The results obtained were analyzed by means of SPSS $® 17$ for Mac OS statistical software and then subjected to meta-analysis in order to find possible significant differences.

No implants failures have been reported during observation period with a survival rate of $100 \%$ at 3 years followup; 180 measures of the implant/cortical marginal bone distance have been collected while 432 measures of perimplant probing have been collected.

The measurements achieved evidenced moderate peri-implant bone resorption both during healing phase both during loading phase. The highest resorption value was $1 \mathrm{~mm}$ in just one implant (ig. 2) while the mean value detected was $0.25 \pm 0,16 \mathrm{~mm}$.

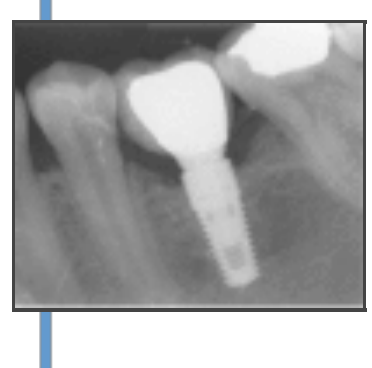

\section{Figure 2}

Periapical $\mathrm{x}$-ray at 12 months; notice the $1 \mathrm{~mm}$ bone resorption.

The probing performed after temporary crowns insertion were always in the limit of biological width, the mean value was $2,05 \pm 0,56 \mathrm{~mm}$; the highest value was $4 \mathrm{~mm}\left({ }^{6}, \underline{7}\right)$ (Tab. 1$)$.

Table 1

Probing and radiographic measures.

\section{Discussion}

Go to: $\mathbb{v}$ Go to:

The innovative Synthegra ${ }^{\circledR}$ surface, based on the use of laser source properly directed, allows the realization of implant surfaces with micro-geometry predetermined avoiding the need of contaminants. Through the laser titan ablation millions micrometrical holes are produced perfectly symmetrical in dimension $(20 \mu \mathrm{m})$, shape (circular concave), and distribution ( $30 \mu \mathrm{m}$ from the center of adjacent holes). The implant surface obtained is contaminants free differently from other type of implant surface $(\underline{-}-\underline{12})$.

In our study, within the limit of the number of implants observed, we found minimal bone resorption in implants flash to the bone inserted both with submerged technique, both with non submerged technique (ㅍig, $\underline{3}$ ).

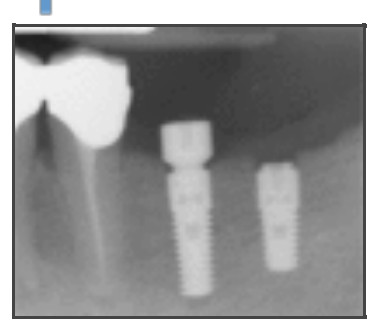

\section{Figure 3}

Implants inserted with submerged and non-submerged technique.

The implant insertion following non-submerged technique permits the increase of intra-sulcular space, restablishing correct biological width clinical visible through increased muco-gengival tunnel.

Further investigations should be focalized on the cause of peri-implant tissues loss morphology and on long term stability control of peri-implant/muco-gengival complex (igs. 4 , $\underline{5})$.

\section{Figure 4}

Muco-gengival Tunnel. 
Clinical and radiographic evaluation of the new implant surface demonstrated that acceptable stability of periimplant parameters both for soft tissues (probing, cheratinized gingiva and papilla) both for hard tissues (periapical x-rays) can be achieved independently from the surgical technique used. The results obtained in this study can be superimposed with those encountered in literature with different implant system. It's highly probable that a micro-roughened controlled and uniform surface, without chemical alterations, could favor adhesion, proliferation and differentiation of osteoblasts on the implant surface. As a conclusive consideration, non submerged technique proved to be more reliable allowing wider peri-implant attached gingiva and avoiding the need of a second surgical procedure to substitute the cover screw with the healing screw.

1. Cecchinato D, Olsson C, Lindhe J. Submerged or non-submerged healing of endosseous implants to be used in the rehabilitation of partially dentate patients. Journal of Clinical Periodontology. 2004;31:299-308. [PubMed]

2. Albrektsson T, Zarb G, Worthington P, Ericsson R. The long-term efficacy of currently used dental implants: a review and proposed criteria of success. International Journal of Oral \& Maxillofacial Implants. 1986;1:11-25. [PubMed]

3. Albrektsson T, Zarb GA. Current interpretations of the osseointegrated response: clinical significance. The International journal of prosthodontics. 1993;6(2):95-105. [릴ed]

4. Abrahamsson I, Berglundh T. Tissue characteristics at microthreaded implants: an experimental study in dogs. Clinical Implant Dentistry \& Related Research. 2006;8:107-113. [ubMed]

5. Nickenig H-J, Wichmann M, Schlegel KA, Nkenke E, Eitner S. Radiographic evaluation of marginal bone levels adjacent to parallel-screw cylinder machined-neck implants and rough-surfaced microthreaded implants using digitized panoramic radiographs. Clin Oral Implants Res. 2009 Jun;20(6):550-4. [PubMed]

6. Tarnow D, Elian N, Fletcher P, Froum S, Magner A, Cho SC, Salama M, Salama H, Garber D. Vertical distance from the crest of bone to the height of the inter-proximal papilla between adjacent implants. Journal of periodontology. 2003;74:1785-88. [PubMed]

7. Lee DW, Park KH, Moon IS. Dimension of interproximal soft tissue between adjacent implants in two distinctive implant systems. J of Periodontology. 2006;77:1080-84. [PubMed]

8. Morra M, Casinelli C, Bruzzone G, Capi A, Di Santi G, Giardino R, Fini M. Surface chemistry effects of topographic modification of titanium dental implant surfaces: 1. Surface analysis. J Oral Maxillofacial Implant. 2003;18:40-45. [PubMed]

9. Behneke A, Behneke N, d'Hoedt B. A 5-year longitudinal study of the clinical effectiveness of ITI solid-screw implants in the treatment of mandibular edentulism. International Journal of Oral \& Maxillofacial Implants. 2002;17:799-810. [PubMed]

10. Astrand P, Engquist B, Anzen B, Bergendal T, Hallman M, Karlsson U, Kvint S, Lysell L, Rundcrantz T. Non-submerged and sub-merged implants in the treatment of the partially edentulous maxilla. Clinical Implant Dentistry \& Related Research. 2002;4:115-127. [PubMed] 
12. Quirynen M, Naert I, van Steenberghe D, Dekeyser C, Callens A. Periodontal aspects of osseointegrated fixtures supporting a partial bridge. An up to 6-year retrospective study. Journal of Clinical Periodontology. 1992;19:118-126. [ubMed]

Articles from Oral \& Implantology are provided here courtesy of CIC Edizioni Internazionali 